\title{
EVALUATION OF ARGENTINE WILD SUNFLOWER BIOTYPES FOR DROUGHT STRESS DURING REPRODUCTIVE STAGE
}

\author{
Fernández-Moroni, I. , Fraysse, M., Presotto, A., Cantamutto, M.
}

Departamento de Agronomía, Universidad Nacional del Sur, San Andrés 800, 8000 Bahía Blanca, Argentina

Received: October 26, 2012

Accepted: December 01, 2012

\section{SUMMARY}

As in several regions where sunflower production has moved to areas with limiting water availability, the search for water-stress tolerant genotypes has been intensified. Helianthus annuus ssp. annuus L. constitutes a potential genetic resource because it has naturalized in the semi-arid zone of central Argentina. The assessment of these genetic materials for water deficit tolerance is of interest because they may represent a source of genes for drought tolerance, useful to sunflower breeding. Drought resistant genotypes should be achieved using easily identified phenotypic traits. Parameters like leaf area are widely used to characterize the performance under stress. Leaf temperature is an easily measured physiological parameter that allows an indirect estimate of plant transpiration and is well correlated with water availability. Relative water content indicates the ability to retain water from the soil and expresses plant osmotic adjustment ability. Specific leaf area is a morphological parameter related to leaf thickness.

The objectives of this study were to evaluate the drought tolerance of Argentine wild sunflower biotypes and identify morphological and physiological traits expressing differences between stressed biotypes.

Wild biotypes were evaluated during three years in the experimental field of the Agronomy Department, Universidad Nacional del Sur, Argentina. Groups of 10-15 plants of each biotype were evaluated under two water conditions, drought (deficit supply) with drip irrigation to cover a half of the potential evapotranspiration during flowering, or with optimal water supply. Soil surface was covered with black polyethylene to exclude rainwater. Wild sunflower comprised five biotypes collected from different habitats in the semiarid region of Argentina. Crosses between the wild biotypes and inbred lines were also included every year. Inbred lines and a commercial hybrid (DK4000) were used as controls. Recorded traits were: plant height, stem diameter, petiole length, leaf area, leaf number, head number and reproductive surface. Leaf parameters were: relative water content (RWC), specific leaf area (SLA), canopy temperature (CT), and chlorophyll content (SPAD). A susceptibility index (SI) was obtained to compare the performance under water stress with that obtained in

* Corresponding author: e-mail: fernandez_ivana@yahoo.com.ar 
optimal conditions. Biotype evaluation and parameter characterization were performed separately for each year because water stress levels were different.

Wild sunflower responses to water stress were different for all parameters among biotypes, except for plant height and petiole length. Wild biotypes had better RWC and lower SLA than cultivated biotypes. Under water stress wild biotypes showed higher values and greater range of RWC and SPAD than cultivated sunflower. Susceptibility index showed that leaf area of wild sunflower biotypes had lower stress susceptibility than cultivated sunflowers. Nevertheless, wild biotypes showed increased susceptibility to the remaining plant morpho-physiological parameters. RWC and CT had a significant relationship in wild sunflower biotypes under water stress.

Drought tolerant type identification was complex because of the complex responses among parameters. Wild biotypes might have a physiological mechanism which allows higher RCA than cultivated sunflower under drought stress. The lower SLA under water deficit could be attributed to a greater leaf thickness and could be related with RCA. Lower leaf area reduction under stress in wild sunflower is an interesting trait that might be used to improve cultivated sunflower. As the RWC is related with CT under stress in wild biotypes, this trait evaluation allows the fast examination of a high number of plants.

The assessment of Argentina wild sunflower biotypes for traits associated with drought tolerance has not yet been done. Their identification could increase sunflower crop yield under drought in semiarid regions.

\section{Key words: Helianthus, drought stress, sunflower, tolerance}

\section{INTRODUCTION}

In several regions sunflower production has moved to areas where water availability is a limiting factor (Rauf and Sadaqat, 2007). Water is one of the most important ecological factors determining crop growth and development, and plays a very important role in crop yield losses. For this reason the search for water stress tolerant genotypes should be intensified. Helianthus annuus ssp. annuus L. constitutes a potential genetic resource because it has naturalized in the semi-arid zone of central Argentina. The assessment of these genetic materials for tolerance to water deficit matters because they represent a source of genes for drought tolerance, useful to sunflower breeding. Drought resistant genotypes should be achieved using phenotypic traits easy to identify. Parameters such as leaf area are widely used to characterize the performance under stress. Leaf temperature is an easily measured physiological parameter that allows an indirect way to estimate plant transpiration and is well correlated with water availability. Relative water content indicates the ability to retain water from the soil and expresses plant osmotic adjustment capacity (Blum, 1989). Specific leaf area is a morphological trait related to leaf thickness. The assessment of Argentine wild sunflower biotypes for traits associated with drought tolerance has not yet been done. The identification of characters that could possibly increase sunflower yield under drought is important because crop is circumscribed to semiarid regions (ASAGIR, 2011). The objectives of this study were 
to evaluate drought tolerance in Argentina wild sunflower biotypes and identify morphological and physiological characters expressing differences between stressed biotypes.

\section{MATERIALS AND METHODS}

Sunflowers biotypes were grown during three years in the experimental field of the Agronomy Department, Universidad Nacional del Sur, Bahía Blanca (38 $42^{\prime} \mathrm{S}$ $62^{\circ} 16^{\prime} \mathrm{W}$ ), Argentina. Groups of 10-15 plants of each biotype were evaluated under two water conditions, drought (deficit supply, -IR) with drip irrigation to cover half of the potential evapotranspiration during flowering, or with optimal water supply (+IR). Three replicates for each water condition were used. Each one consisted of a macro plot containing all the biotypes. Soil surface was covered with black polyethylene to exclude rainwater. Wild sunflower comprised five biotypes collected in different habitats in the semiarid region of Argentina. Crosses between the wild biotypes and inbred lines were also included every year. Inbred lines and a commercial hybrid (DK4000) were used as control. Recorded traits were: plant height, stem diameter, petiole length, leaf area, leaf number, head number and reproductive surface. Leaf parameters were relative water content (RWC), specific leaf area (SLA), canopy temperature (CT), and chlorophyll content (SPAD, Minolta). Plant traits were measured in three summer seasons, whereas leaf parameters were estimated in two seasons. A susceptibility index (SI) was obtained, which compares performance under water stress with that obtained in optimal conditions, where $\mathrm{SI}=\left(\mathrm{X}_{+\mathrm{IR}}-\mathrm{X}_{-\mathrm{IR}}\right)$, with $\mathrm{X}$ being the evaluated parameter. Biotype evaluation and parameter characterization were performed separately for each year because water stress levels were different. The three summer seasons (2008-2009; 2009-2010 and 2010-2011) were categorized based on their recorded rainfall and evapotranspiration during spring and summer, establishing a simple water balance (rainfall $\mathrm{mm}$ minus referenced evapotranspiration $\mathrm{mm}$ ), in high (2008-2009) and low stress seasons (2009-2010 and 2010-2011). Respective season water balance: -1072 mm, $765 \mathrm{~mm}$ and $-786 \mathrm{~mm}$.

\section{RESULTS AND DISCUSSION}

Main differences in plant parameters were found between biotypes only in high water stress season. Under this condition wild sunflower biotypes expressed major changes in their plant structure under water stress. This might be an adaptation to an imposed water restrictive regime. Except for plant height and petiole length, wild sunflowers did not respond to stress in the same way. Wild-crop hybrids and cultivated sunflower only varied in plant height and petiole length under this condition (Table 1). The imposed water stress in the remaining summer seasons did not cause a significant reduction in plant parameters in the studied biotypes (Table 1). 


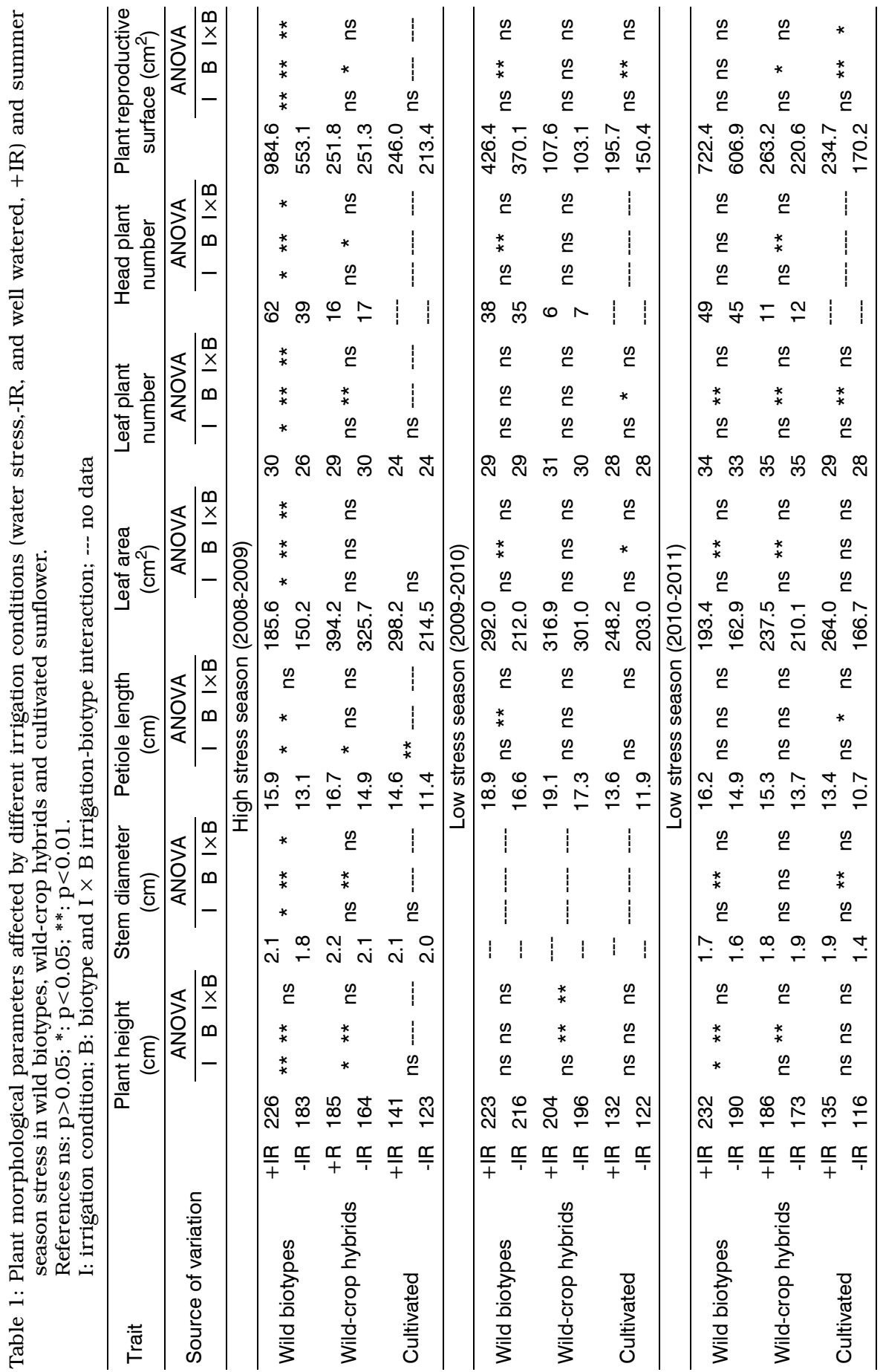


AAL and RIV wild biotypes maintained their reproductive surface under stress, but they showed a different strategy. Whereas RIV reduced leaf area only, AAL decreased plant height, leaf number and petiole length in order to adapt to the new condition (Table 2). Wild-crop hybrids and cultivated sunflower reduced petiole length, but they had no reduction in leaf area. This strategy would save resources to keep leaf area and reproductive surface (Table 1). Maintaining reproductive surface under water stress would indicate that the biotype is able to tolerate stress (Blum, 2005).

Table 2: Plant morphological traits affected by different conditions of irrigation in high water stress season (2008-2009), in wild sunflower biotypes.

ns: $\mathrm{p}>0.05 ;{ }^{*}: \mathrm{p}<0.05{ }^{* *}: \mathrm{p}<0.01$

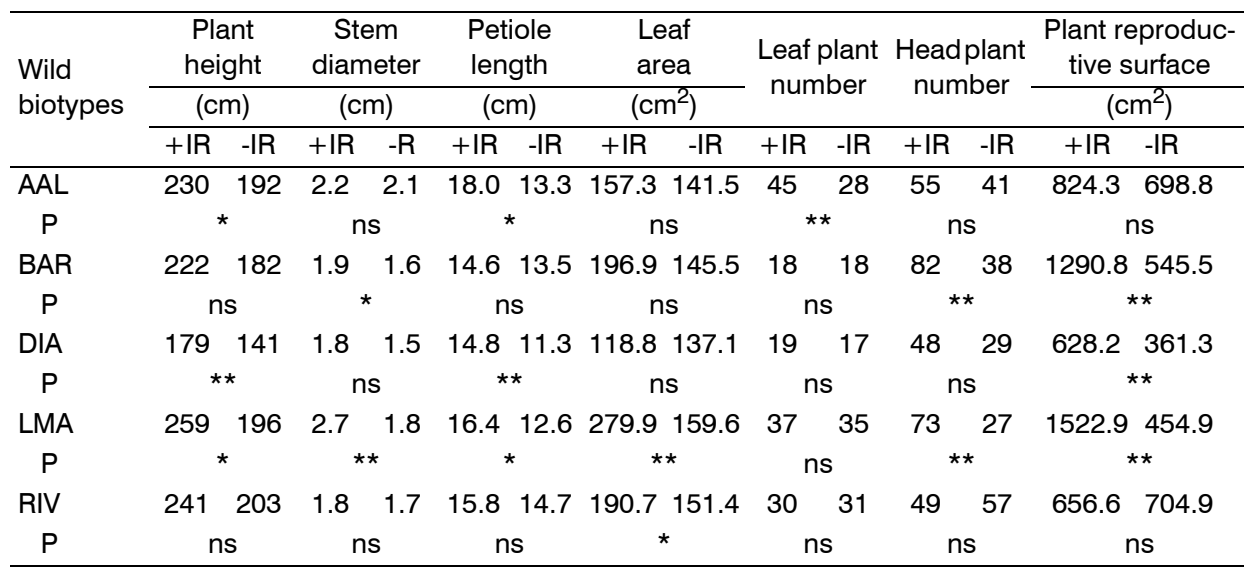

Wild biotypes had better RWC (Table 3) and showed greater range of RWC under stress than cultivated biotypes (data not shown). This indicates that some wild sunflowers could have a physiological mechanism to retain water under stress, which is necessary for normal metabolic function (Blum, 1989). This feature deserves further study.

Table 3: Relative water content (RWC), specific leaf area (SLA) and chlorophyll (SPAD) under stress (-IR) and well watered (+IR) conditions, during two water stress seasons. References: ns: $\mathrm{p}>0.05$; $^{*}: \mathrm{p}<0.05 ;{ }^{* *}: \mathrm{p}<0.01$. I: irrigation condition; $\mathrm{B}$ : biotype and I $\mathrm{x}$ B irrigation-biotype interaction

\begin{tabular}{|c|c|c|c|c|c|c|c|c|c|c|c|c|c|c|c|}
\hline & \multicolumn{5}{|c|}{ RWC (\%) } & \multicolumn{5}{|c|}{$\mathrm{SLA}\left(\mathrm{mm}^{2} \cdot \mathrm{mg}^{-1}\right)$} & \multicolumn{5}{|c|}{ SPAD } \\
\hline & \multirow{2}{*}{$+\mathrm{IR}$} & \multirow{2}{*}{$-I R$} & \multicolumn{3}{|c|}{ ANOVA } & \multirow{2}{*}{$+\mathrm{IR}$} & \multirow{2}{*}{$-I R$} & \multicolumn{3}{|c|}{ ANOVA } & \multirow{2}{*}{$+\mathrm{IR}$} & \multirow{2}{*}{$-\mathrm{IR}$} & \multicolumn{3}{|c|}{ ANOVA } \\
\hline & & & $\mathrm{I}$ & $\mathrm{B}$ & $\mathrm{I} \times \mathrm{B}$ & & & I & $\mathrm{B}$ & $1 \times B$ & & & I & $\mathrm{B}$ & $I \times B$ \\
\hline \multicolumn{16}{|c|}{ High stress season (2008-2009) } \\
\hline Wild biotypes & 59.7 & 56.8 & ns & ** & ns & 11.9 & 10.8 & ns & * & ns & 40.8 & 43.1 & * & * & ns \\
\hline Wild-crop hybrids & 44.4 & 42.8 & ns & ns & ns & 12.4 & 11.4 & ns & ns & ns & 43.4 & 45.2 & * & ** & ns \\
\hline Cultivated & 47.2 & 40.7 & ns & $\mathrm{ns}$ & ns & 14.2 & 13.8 & ns & * & ** & 39.4 & 40.5 & ns & ns & ns \\
\hline \multicolumn{16}{|c|}{ Low stress season (2010-2011) } \\
\hline Wild biotypes & 82.6 & 77.1 & ns & ns & ns & 12.3 & 11.2 & ns & ns & ns & 38.4 & 38.8 & ns & $\star$ & ns \\
\hline Wild-crop hybrids & 81.1 & 74.7 & $\star \star$ & ns & ns & 13.0 & 11.5 & ns & ns & ns & 35.8 & 36.5 & ns & * & ns \\
\hline Cultivated & 81.6 & 72.2 & $\star \star$ & ns & ns & 13.3 & 13.4 & ns & ns & ns & 33.0 & 34.2 & ns & * & ns \\
\hline
\end{tabular}


SLA did not change under stress in any of the studied biotypes. Cultivated biotypes had higher SLA than wild ones (Table 3). Wild sunflower biotypes exhibited higher SPAD value (Table 3) and range than cultivated sunflower (data not shown). SPAD values were higher under water stress in wild sunflowers and wild-crop hybrids in high stress season (Table 3). This could be attributed to an increase in chlorophyll concentration probably due to a reduction in plant size. However, leaf chlorophyll can be an estimate of the relative stress injury in terms of chlorophyll breakdown (www.plantstress.com, 2011), so this change could indicate that chlorophyll is still functional.

The susceptibility index showed that wild sunflower biotypes leaf area had lower stress susceptibility than cultivated sunflower. Nevertheless, wild biotypes showed increased susceptibility for the rest of plant morpho-physiological parameters evaluated (Table 4). Plant parameters evaluated through this index could not be realistic, because wild, cultivated and wild-crop biotypes have large differences in plant structure.

Table 4: Plant susceptibility indexes in wild biotypes, wild-crop hybrids and cultivated sunflower, under three water stress seasons. Means with the same letters were not different in Tukey test. References ns: $\mathrm{p}>0.05 ;^{*}: \mathrm{p}<0.05 ;^{* *}: \mathrm{p}<0.01$. --- no data

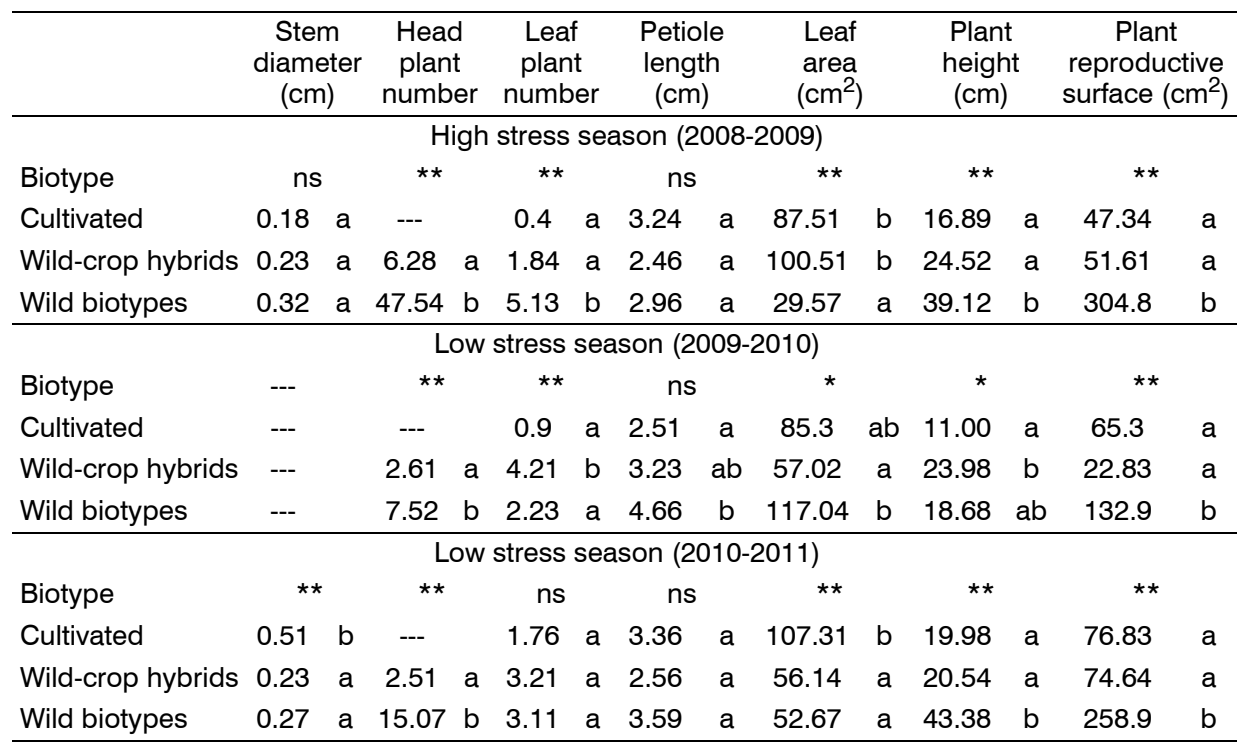

Wild sunflowers had less susceptibility to decrease RWC under water stress than the commercial hybrid, DK4000 (Table 5). Within wild biotypes, besides maintaining RWC, RIV had low change in SLA but enhanced susceptibility to increase CT under stress in both seasons. Instead, DIA had low change in CT, but great susceptibility to SLA and RWC (Table 5).

Linear relationships were obtained for CT and SLA with RWC for wild, wildcrop and cultivated sunflower, taking into account irrigation conditions and 


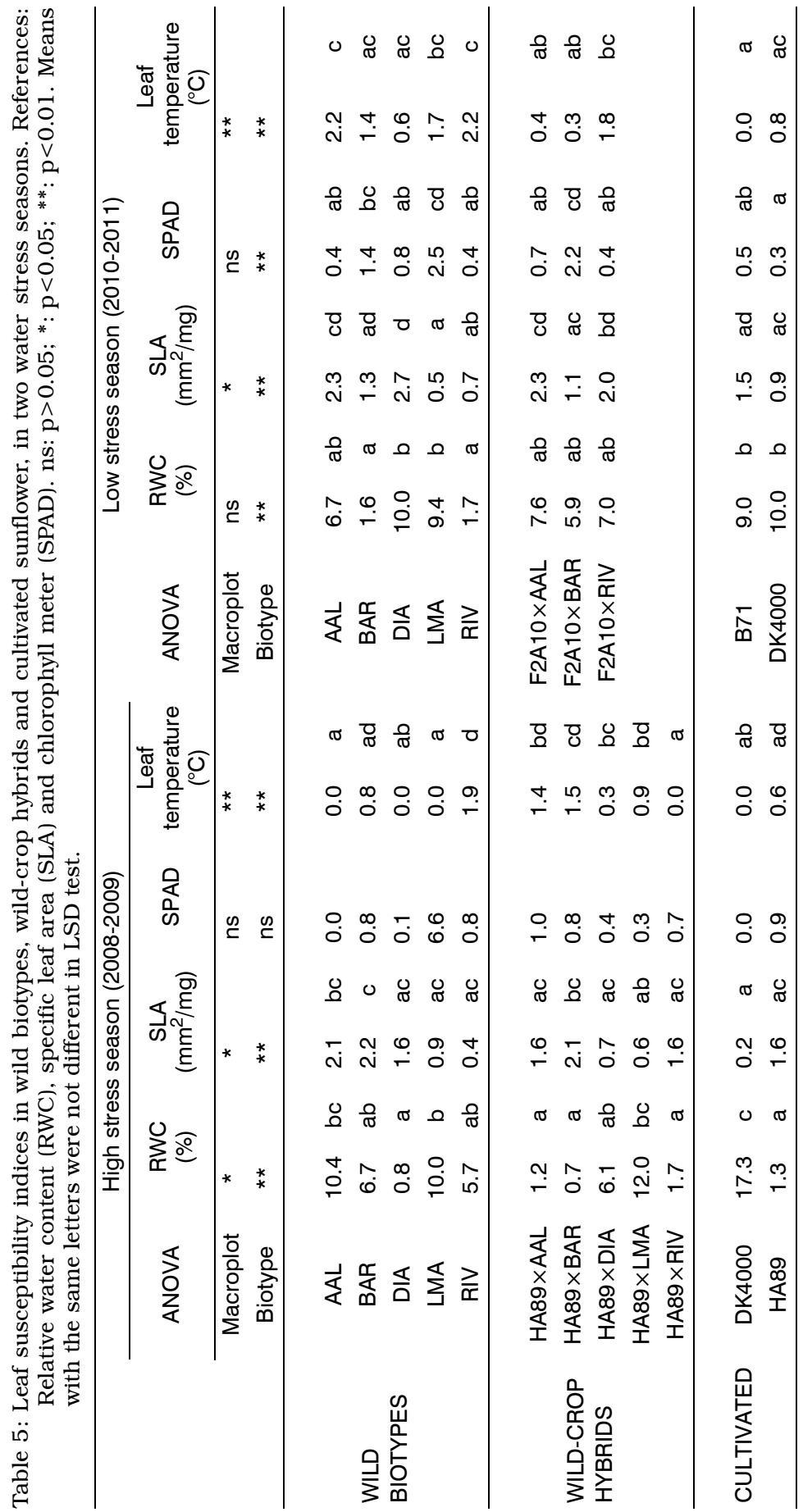


imposed stress for summer season. For wild sunflower biotypes when RWC increased CT decreased under water stress in both experimental conditions $\left(\mathrm{R}^{2}=\right.$ $\left.0,4^{* *} ; \mathrm{R}^{2}=-0,34^{* *}\right)$, but this relationship was not found under the well watered condition. This could be important because finding biotypes with high RWC might be achieved by a simple and less time consuming technique, such as CT.

In high stress season wild sunflowers and their wild-crop hybrids had significant negative relationships between SLA and CRA, under water limited irrigation. The same was found for cultivated biotype but only under well irrigated conditions. In the same period, CT and RWC presented negative relations for wild-crop and cultivated sunflowers.

\section{CONCLUSIONS}

The identification of drought tolerant types is difficult because each biotype showed complex responses in the evaluated parameters, and water stress strength also influences the response. Beyond this, wild biotypes showed variation in all parameters, with some biotypes showing traits that could improve water stress tolerance.

Wild biotypes likely have a physiological mechanism that allows them to retain higher RWC than cultivated sunflower under drought stress. The lower SLA under water deficit perhaps is due to thicker leaf and could be related with sustained RWC. The lower reduction of leaf area under stress in wild sunflowers is an interesting trait that might be used for sunflower breeding. As the RWC is related with CT under stress in wild biotypes, this trait evaluation allows faster examination of a higher number of plants.

We found that wild biotypes RIV and AAL maintained reproductive surface as cultivated sunflower, with high water stress. RIV had the ability to retain RWC also under stress. Further rigorous studies under water stress should be done to establish RIV and AAL tolerance.

\section{REFERENCES}

ASAGIR, 2011. Asociación Argentina de Girasol. Available on line at: http://www.asagir.org.ar/ asagir2008/

Blum, A., 1989. Breeding methods for drought resistance. In: Jones, H.G., Flowrs, T.J., Jones, M.B., (eds.) Plant under stress. Cambridge University Press. Pp. 197-215.

Blum, A. 2005. Drought resistance, water-use efficiency, and yield potential - are they compatible, dissonant, or mutually exclusive? Australian Journal of Agricultural Research 56: 1159-1168.

Plant stress, 2011. Available on line at: http://www.plantstress.com/methods/index.asp

Rauf. S. and Sadaqat, H., 2007. Sunflower (Helianthus annuus L.) germplasm evaluation for drought tolerance. Communications in Biometry and Crop Science 2(1): 8-16. 